\title{
Ending in the Definition of the Ancient Greek Word "Eion"
}

Dreams of Eden swirl in thin smoke, turning the night cold as a heart.

Then what is this place we have come to instead, rainbow-colored like scruples?

Yes, I fear it is a rainy spot bringing sweet savors up from the earth, obscene like one's worst.

Still it is our place, sifting light like an eyelash, having on the table its bowl of dried figs.

The inhabitants of that first garden-work, love, birth-linger in some form, and while they are all obedient to laws like an element,

they are also the inevitable beach, that "lower part of the face over which tears flow." 